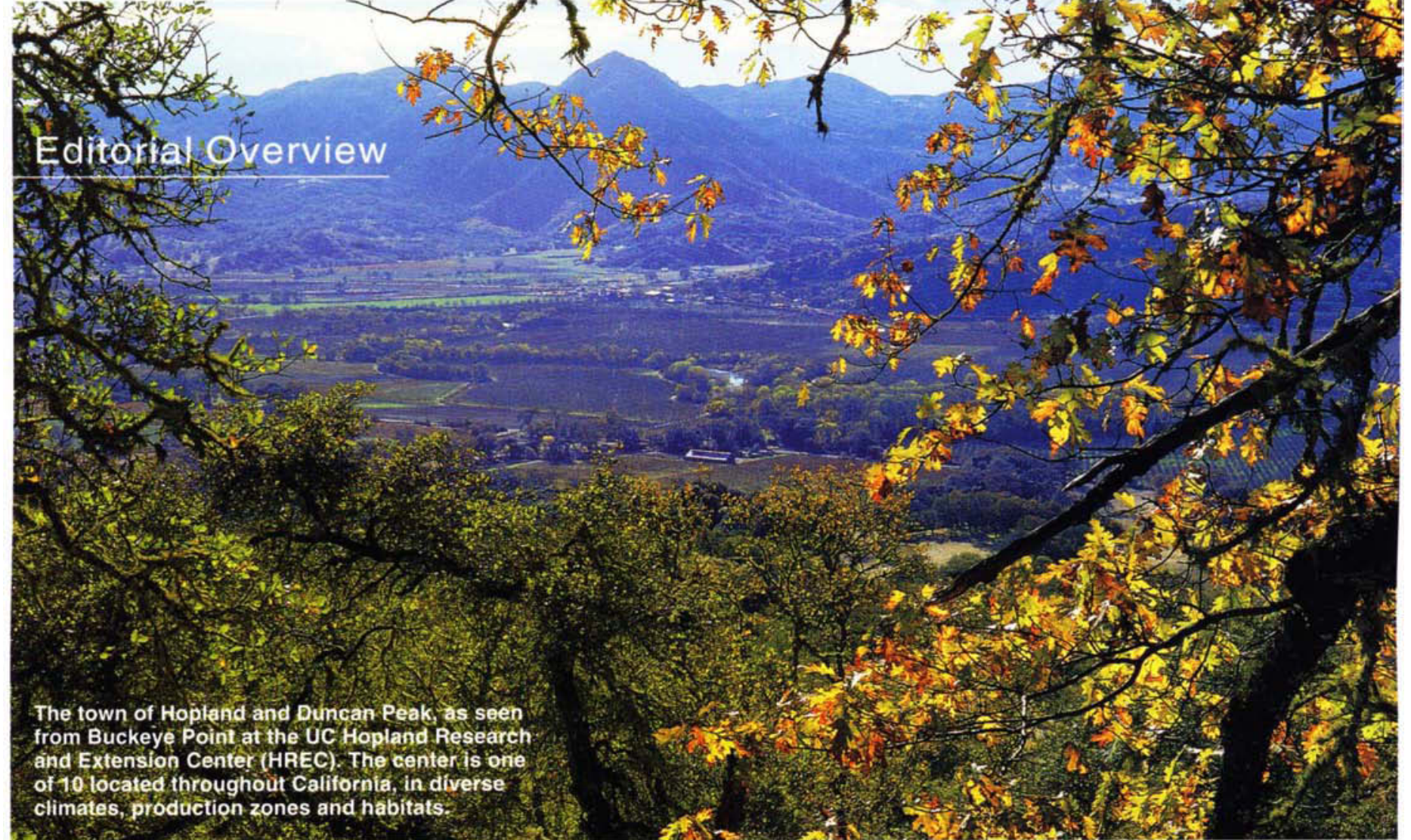

\title{
UC Research and Extension Centers: Statewide system provides local answers to local needs
}

$\mathrm{IN}$ 1951, the University established the Hopland Research and Extension Center (HREC) on what had been a working sheep ranch in Mendocino County. Sheep ranching was then a thriving California industry, and it was appropriate that the center at first emphasized studies of sheep breeding and management, veterinary entomology, native rangelands and wildlife.

Today the Hopland center, which encompasses more than 5,000 acres of rolling and rugged rangeland, has evolved to match the needs of the surrounding agriculture and California as a whole. It currently supports 37 projects that span both traditional and new disciplines, and address both urban and agricultural needs.

This issue commemorates the 50th anniversary of the HREC with publication of some of the center's current research - research informed by findings from past decades. Articles discuss emerging diseases, oak woodland ecology, watershed management, sheep and wildlife management, and vegetation change. Hopland's landmark investigations are cited, including studies of the center's herd of Columbian blacktailed deer, and ongoing investigations that have yielded the most comprehensive database for parasites associated with any species of deer. In addition, the issue summarizes 30 years of selec- tive breeding of sheep for suitability to the Hopland environment, a remarkable example of long-term genetic trials conducted on domestic animals.

Hopland is one of 10 UC Research and Extension Centers (RECs) located throughout the state's diverse production and climate zones. Each center offers unique opportunities for onsite research and education. As a whole the centers permit scientists to work on any of the hundreds of crop and livestock commodities grown in the state.

Intermountain. For example, starting with the introduction of horseradish in the early 1950s, Intermountain REC research has resulted in the adoption of many new crops and improved crop varieties in the mountain valleys of Northern California.

Sierra Foothill. Sierra Foothill REC has supported oak woodland research to determine why native oaks are not regenerating adequately. Their investigations have also contributed to modern, environmentally sensitive, beef cattle-management systems.

Bay Area. Turfgrass research from the Bay Area REC has enabled homeowners and turfgrass managers to select the turfgrass cultivars best suited to California's Central Coast climate.

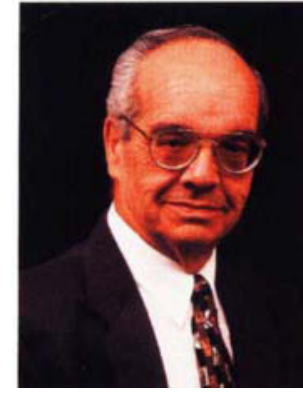

W.R. GOMES Vice President, Agriculture and Natural Resources 


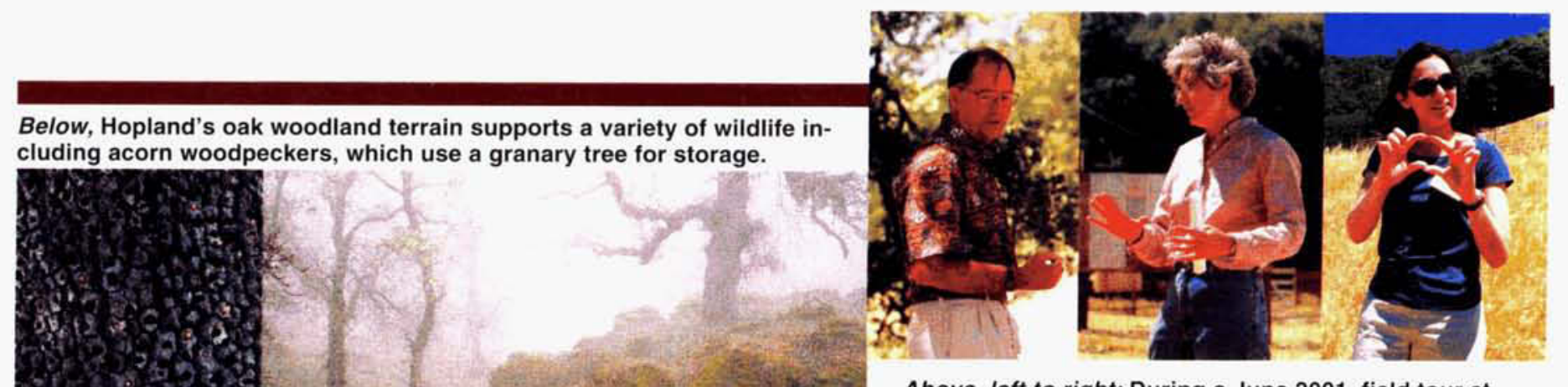

Above, left to right: During a June 2001, field tour at Hopland, UC Davis animal science professor Ed Price explains sheep behavior research; UC Cooperative Extension viticulture advisor Rhonda Smith describes vineyard irrigation work; UC Berkeley Ph.D. candidate Valerie Eviner discusses nutrient cycling.

Photos by Phil Schermeister.

Kearney. With 25 permanent faculty, Kearney REC scientists have developed new fruit, nut and grape varieties, introduced innovative cultural and irrigation practices, and introduced and adapted new pest and disease management techniques.

West Side. West Side REC scientists have pioneered saline drainage-water management options that are critically needed in this region of the state. Their furrow and drip irrigation methods, and fertilization practices, have been widely adopted by tomato and cotton growers throughout the Central Valley.

Lindcove. Lindcove REC maintains the Citrus Clonal Protection Program's foundation budwood orchard for disease-free citrus. More than 100 different selections of citrus are in this collection, making important budwood available to California nurseries and growers.
Shafter. Researchers at the Shafter REC have reduced the use of pesticides in cotton production by identifying six new biological control agents of the cotton aphid. Shafter exemplifies the collaborative potential of RECs by housing both UC and U.S. Department of Agriculture researchers at the same site and partnering with the cotton industry to focus research on the many issues facing cotton production statewide.

South Coast. Research at the South Coast REC has yielded important strawberry varieties now used in California and throughout the world. In 2000 almost half of the acreage of the $\$ 800$ million California strawberry crop was planted to Camarosa, a prolific variety developed at South Coast REC and introduced in 1994.

Desert. Research at the Desert REC, the first center that was established in 1912, has led to effective strategies for silverleaf whitefly control includ-

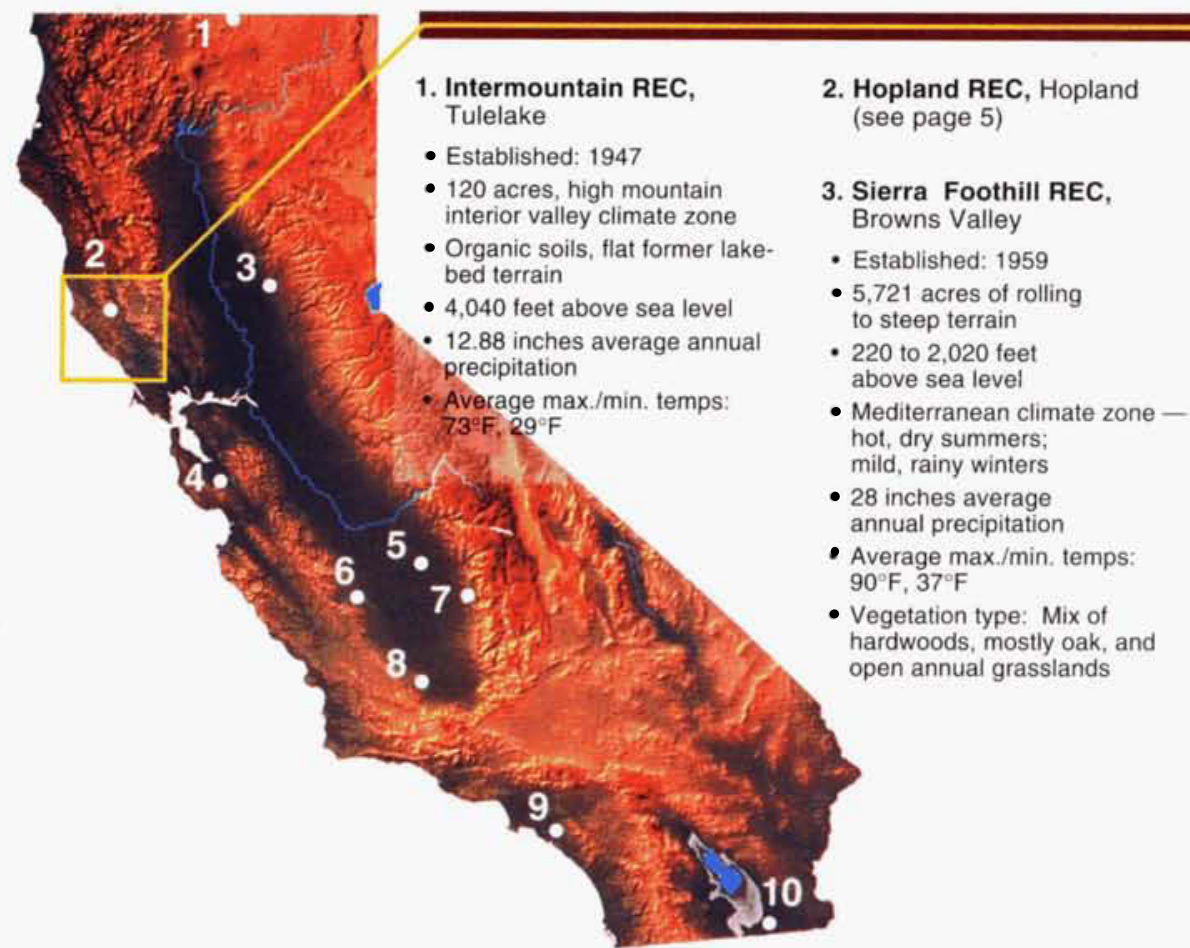

4. Bay Area REC, Santa Clara

- Established: 1920

- 17 acres

- Interior coastal valley climate zone

- Flat alluvial plain terrain

- 60 feet above sea level

- 13.11 inches annual precipitation

- Average max./min. temps: $68^{\circ} \mathrm{F}, 49^{\circ} \mathrm{F}$

\section{Kearney REC, Parlier}

- Established: 1962

- 330 acres

- Mediterranean climate zone

- Flat alluvial plain terrain

- 337 feet above sea level

- 10.6 inches annual precipitation

- Average max./min. temps: $95^{\circ} \mathrm{F}, 39^{\circ} \mathrm{F}$

- 1,123 mean annual chilling hours below $45^{\circ} \mathrm{F}$
6. West Side REC, Five Poin

- Established: 1959

- 320 acres

- Semi-arid Mediterranean climate zone

- 280 feet above sea level

- Average max./min. temps: $89^{\circ} \mathrm{F}, 38^{\circ} \mathrm{F}$

7. Lindcove REC, Exeter

- Established: 1959

- 175 acres

- Mediterranean climate zonehot, dry summers; mild winte

- Gently sloping alluvial fan terrain

- 500 feet above sea level

- 13 inches annual precipitatio prolonged tule fog (Decembe and January

- Average max./min, temps: $96^{\circ} \mathrm{F}, 42^{\circ} \mathrm{F}$ 
ing development of a whitefly-resistant alfalfa variety.

Each of the 10 centers pursues research of regional interest. Scientists study problems under local conditions one step removed from conditions on the farm. Their findings are relevant to area farmers because they share common soil, climate and geography.

Could such research be done in cooperation with growers, using land on nearby farms? Unfortunately, many such trials would have an unacceptable economic impact on working farms. Research requires rigorous controls, typically over several years. It can entail destruction of produce and often involves a wide range of fertilizer, pesticide and water application rates. It can create potential risks from unregistered applications of pesticides or inoculation of plants with specific diseases. Indeed, when conditions permit, much of our "next stage" research is conducted on cooperating farms.

More than 170 University scientists currently conduct nearly 400 research projects on the RECs. Each center provides specialized facilities and equipment and the technical staff required to manage commodities grown. Those facilities include greenhouses, laboratories, livestock handling and feeding facilities, postharvest equipment and controlled-atmosphere chambers.

The system also serves as an educational resource for students, providing hands-on learning opportunities through work-study programs,

8. Shafter REC, Shafter

- Established: 1921

- 100 acres

- Central Valley,

Mediterranean zone

- Flat plain terrain

- 364 feet above sea level

- 6.30 inches annual precipitation

(72-year average)

- Average max./min. temps $96^{\circ} \mathrm{F}, 35^{\circ} \mathrm{F}$
9. South Coast REC, Irvine

- Established: 1956

- 200 acres

- Coastal plain/temperate climate zone

- Medium-sloped, local alluvial tan terrain

- 400 feet above sea level

- 13.16 inches annua precipitation (72-year average

- Average max./min. temps: $71^{\circ} \mathrm{F}, 53^{\circ} \mathrm{F}$

10. Desert REC, El Centro

- Established: 1921

- 255 acres

- Interior desert valley

- Flat alluvial plain

- 60 feet below sea level

- Average max./min. temps: $106^{\circ} \mathrm{F}, 54^{\circ} \mathrm{F}$ field trips, short courses and graduate student research. Participants are not only from UC, but also from California State University campuses, community colleges and $\mathrm{K}-12$ programs.

Helping growers and ranchers with regionspecific data and technical guidance provides benefits to all Californians. Such data enable growers and ranchers to produce bountiful, high-quality food and fiber using methods appropriate to local conditions.

In this fashion, we at UC can continue to apply the best of research findings from our laboratories to the needs of all California citizens where they are - that is, the RECs help us in our effort to bring the University to the people.

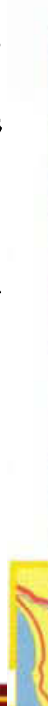

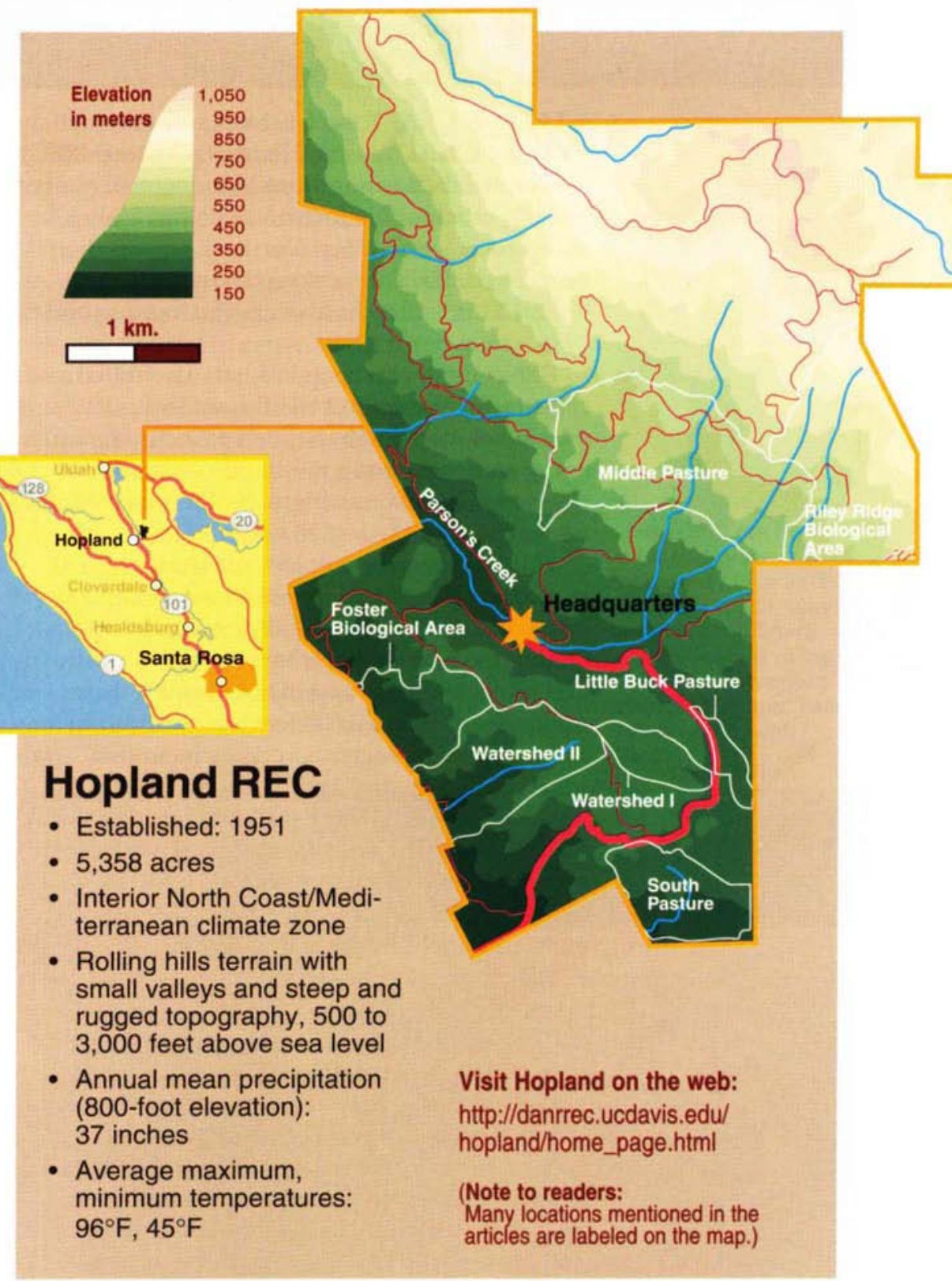

